\title{
Farelo de soja na alimentação de tilápias-do-nilo durante o período de reversão sexual
}

\author{
Fábio Meurer ${ }^{1}$, Carmino Hayashi ${ }^{2}$, Leandro Martins Barbero ${ }^{3}$, Lilian Dena dos Santos ${ }^{3}$, Robie \\ Allan Bombardelli ${ }^{4}$, Leda Maria Saragiotto Colpini ${ }^{1}$ \\ ${ }^{1}$ Curso de Zootecnia - Fundação Universidade Federal do Vale do São Francisco (UNIVASF), Campus da Fazenda Experimental, Caixa \\ Postal 252 - Petrolina - PE. \\ ${ }^{2}$ Centro Avançado de Pesquisa Tecnológica do Agronegócio de Pescado Continental, APTA/SAA, São José do Rio Preto, SP \\ 3 Pós-Graduação em Zootecnia (PPZ), Universidade Estadual de Maringá (UEM). \\ ${ }^{4}$ Curso de Engenharia de Pesca, Universidade do Oeste do Estado do Paraná (UNIOESTE).
}

RESUMO - Foram utilizadas 800 larvas com 2 dias de idade com o objetivo de testar o uso de farelo de soja em rações para tilápias-do-nilo durante o período de reversão sexual (30 dias). O experimento foi conduzido segundo delineamento em blocos casualizados com quatro tratamentos e quatro repetições, no qual um tanque-rede com 50 larvas correspondeu a uma unidade experimental. Os tratamentos consistiram de rações isoprotéicas e isoenergéticas (38,6\% de proteína digestível e $3.800 \mathrm{kcal} / \mathrm{kg}$ de energia digestível) com 0,16 , 34 ou 42\% de farelo de soja. O aumento no nível de farelo de soja teve efeito linear positivo sobre os valores de peso e comprimento finais médios, mas não afetou a condição corporal e os índices de sobrevivência. Recomenda-se incluir o farelo de soja em níveis de até $42 \%$ na ração de tilápias-do-nilo na fase de reversão.

Palavras-chave: alevinos, alimento protéico, larvicultura, nutrição, Oreochromis niloticus, peixes

\section{Soybean meal in Nile tilapia diets during the sexual reversion period}

\begin{abstract}
Eight hundred Nile tilapia larvae with two days old were used to evaluate the inclusion of soybean meal in diets fed Nile tilapia during the sex reversion period (30 days). The experiment was analyzed as a completely randomized blocks, with four treatments and four replications. A net tank with 50 larvae was considered an experimental unit. The treatments were formulated to be isoprotein and isonitrogenous (38.6\% of digestible protein and 3,800 kcal/kg of digestible energy), with increasing levels of soybean meal inclusion 0, 16, 34 and 42\%. Average final weight and length linearly increased as the dietary soybean meal levels increased. No treatment effect on survival and body condition was observed. It is recommend to include up to $42 \%$ of soybean meal in Nile tilapia diets in the sexual reversion phase.
\end{abstract}

Key Words: fingerlings, fish, larvae culture, nutrition, Oreochromis niloticus, protein feed

\section{Introdução}

A tilápia-do-nilo é uma espécie de grande interesse para a piscicultura atual, em razão de suas diversas qualidades, como rusticidade em relação a ambientes com baixo oxigênio dissolvido e altas densidades de criação. Outra característica muito importante está relacionada à sua alimentação, que pode ser natural e/ou artificial.

Uma das características das rações comerciais para tilápias na fase de reversão sexual é o alto teor protéico. Algumas fábricas dispõem de rações com até 55\% de proteína bruta (PB) para esta fase, apesar de algumas pesquisas apontarem valores bem mais baixos (Hayashi et al., 2002). Outra característica das rações encontradas no mercado para esta fase é o alto teor de alimentos protéicos de origem animal, como as farinhas de peixe ou de vísceras de aves, entre outros (Meurer et al., 2005). Há poucos trabalhos na literatura com avaliação de alimentos para tilápia-do-nilo nesta fase do desenvolvimento (Boscolo et al., 2005a,b; Meurer et al., 2005; Souza et al., 2004).

Em virtude da alta porcentagem de alimentos de origem animal, um dos problemas destas rações são os altos teores de minerais, como cálcio e fósforo, e o alto custo de algumas destas fontes, como a farinha de peixes de boa qualidade. Um interessante fator de marketing atual é a utilização de alimentos de origem vegetal na composição das rações animais, em decorrência de problemas em passado recente. Alguns pesquisadores têm demonstrado que as fontes 
protéicas de origem animal podem ser substituídas parcial ou totalmente por fontes protéicas de origem vegetal para tilápias-do-nilo (Boscolo et al., 2001).

O farelo de soja é um alimento protéico de boa disponibilidade no mercado nacional e, em razão da alta produção de grão de soja e de seu processamento para extração de óleo, constitui a principal fonte protéica utilizada por animais monogástricos, como aves, suínos e peixes. De acordo com Lovell (1998), entre os alimentos protéicos de origem vegetal, o farelo de soja possui a proteína com o melhor perfil aminoacídico, além de uma concentração de aminoácidos essenciais adequada às exigências dos peixes.

Este trabalho foi realizado para avaliar o efeito do fornecimento de farelo de soja na ração sobre o desempenho e a sobrevivência de tilápias na fase de reversão sexual.

\section{Material e Métodos}

O experimento foi realizado no Laboratório de Aqüicultura do Departamento de Biologia do Centro de Ciências Biológicas da Universidade Estadual de Maringá, durante 30 dias, entre os meses de outubro a novembro de 2002. Foram utilizadas 800 larvas de tilápia-do-nilo, com 2 dias de idade, peso médio de 0,011 $\pm 0,001$ g e 0,95 $\pm 0,01 \mathrm{~cm}$ de comprimento, distribuídos em 16 tanquesrede, em quatro caixas de $1.000 \mathrm{~L}$, em um delineamento em blocos casualizados com quatro tratamentos e quatro repetições. Cada caixa possuía quatro tanques-rede e cada unidade experimental foi constituída de um tanquerede de $200 \mathrm{~L}$ com 50 larvas.

Os tanques-rede possuíam aeração constante por pedras microporosas ligadas por meio de mangueiras a um compressor radial de $3 / 4 \mathrm{cv}$ de potência. A temperatura das caixas foi mantida com o uso de seis aquecedores de $100 \mathrm{~W}$. O número de aquecedores ligados variou conforme a temperatura ambiente, sempre mantendo a temperatura da água das caixas em torno de $26,5^{\circ} \mathrm{C}$. Cada caixa possuía um sistema de renovação de água de $20 \%$ do volume diário total. Semanalmente, foi realizada sifonagem nas caixas para retirarada de fezes e restos de ração. $\mathrm{O}$ pH, a condutividade e o oxigênio dissolvido da água das caixas foram monitorados semanalmente e a temperatura medida diariamente às $8 \mathrm{e} 17 \mathrm{~h}$.

Foram formuladas quatro rações isoprotéicas e isocalóricas (Tabela 1 e 2), de acordo com as exigências nutricionais da espécie nesta fase (Hayashi et al., 2002), considerando-se tratamento o nível de farelo de soja (0,0; 16,0; 34,0 e 42,0\%). Para fabricação das rações, os alimentos foram moídos em peneira de $0,5 \mathrm{~mm}$, misturados de acordo com a formulação e posteriormente acrescidos do hormônio masculinizante (17- $\alpha$-metiltestosterona), $60 \mathrm{mg} / \mathrm{kg}$, conforme descrito por Meurer et al. (2002). As rações foram fornecidas cinco vezes ao dia ( $8 \mathrm{~h}, 9 \mathrm{~h} 30,11 \mathrm{~h} 30,13 \mathrm{~h} 30 \mathrm{e} 17 \mathrm{~h}$ ), conforme recomendação de Sanches \& Hayashi (2001).

No final do período experimental, os peixes de cada unidade experimental foram insensibilizados em água gelada $\left(2^{\circ} \mathrm{C}\right)$ e contados para realização das medidas individuais de peso (g) e comprimento padrão (cm). As variáveis avaliadas foram: peso final, comprimento final, sobrevivência e fator de condição (obtido por meio da expressão wt/lt3 × 100, em que $\mathrm{wt}=$ peso total e lt $=$ comprimento total).

Os dados obtidos no experimento foram submetidos à análise de variância a 5\% de probabilidade e,em caso de diferença, aplicou-se a análise de regressão pelo programa estatístico Sistema de Análise Estatística e Genética - SAEG (UFV, 1997).

Tabela 1 - Composição das rações experimentais (\% da matéria natural)

\begin{tabular}{lcccc}
\hline Ingrediente & \multicolumn{4}{c}{ Nível de farelo de soja (\%) } \\
\cline { 2 - 5 } & 0,00 & 16,00 & 34,00 & 42,00 \\
\hline Milho & 18,87 & 11,71 & 3,66 & 0,08 \\
Farinha de vísceras & 72,98 & 61,80 & 49,22 & 43,63 \\
de aves & & & & \\
Óleo de soja & 6,63 & 8,24 & 10,04 & 10,85 \\
Calcário calcítico & 0,00 & 0,32 & 0,68 & 0,84 \\
Fosfato bicálcico & 0,00 & 0,41 & 0,88 & 1,09 \\
Suplemento mineral & 1,00 & 1,00 & 1,00 & 1,00 \\
e vitamínico & & & & \\
Sal & 0,50 & 0,50 & 0,50 & 0,50 \\
B HT & 0,02 & 0,02 & 0,02 & 0,02 \\
\hline
\end{tabular}

${ }^{1}$ Níveis de garantia por quilograma do produto: vit. A - 1.200.000 UI vit. D3 - 200.000 UI; vit. E - 12.000 mg; vit. K3 - 2.400 mg; vit. B1 $4.800 \mathrm{mg}$; vit. B2 - $4.800 \mathrm{mg}$; vit. B6 - $4.000 \mathrm{mg}$; vit. B12 - $4.800 \mathrm{mg}$; ácido fólico - $1.200 \mathrm{mg}$; pantotenato de cálcio - $12.000 \mathrm{mg}$; vit. C - $48.000 \mathrm{mg}$ biotina - $48 \mathrm{mg}$; colina - $65.000 \mathrm{mg}$; niacina - $24.000 \mathrm{mg}$; Fe - $10.000 \mathrm{mg}$; $\mathrm{Cu}-6.000$ mg; Mn - 4.000 mg; Zn - 6.000 mg; I - 20 mg; Co - 2 mg; Se $-20 \mathrm{mg}$.

Tabela 2 - Composição química das rações (\% da matéria natural $)^{1}$

\begin{tabular}{|c|c|c|c|c|}
\hline \multirow[t]{2}{*}{ Ingrediente } & \multicolumn{4}{|c|}{ Nível de farelo de soja (\%) } \\
\hline & 0,00 & 16,00 & 34,00 & 42,00 \\
\hline $\mathrm{MS}^{1,2,3}$ & 93,40 & 93,23 & 93,04 & 92,97 \\
\hline $\mathrm{ED}(\mathrm{kcal} / \mathrm{kg})^{2,3}$ & $3.800,00$ & $3.800,00$ & $3.800,00$ & $3.800,00$ \\
\hline Proteína digestível ${ }^{2,3}$ & 38,60 & 38,60 & 38,60 & 38,60 \\
\hline PB $(\%)^{1,2,3}$ & 43,85 & 43,77 & 43,68 & 43,64 \\
\hline Amido $(\%)^{3}$ & 11,69 & 7,69 & 3,18 & 1,18 \\
\hline Gordura $(\%)^{1,2,3}$ & 19,18 & 19,08 & 18,97 & 18,92 \\
\hline $\mathrm{FDN}^{3}$ & 2,15 & 3,59 & 5,22 & 5,94 \\
\hline $\mathrm{FB}^{3}$ & 0,36 & 1,01 & 1,73 & 2,05 \\
\hline Metionina + cistina $(\%)^{3}$ & $\begin{array}{ll}3 & 1,90\end{array}$ & 1,77 & 1,63 & 1,56 \\
\hline Ácido linoléico ${ }^{3}$ & 6,42 & 6,88 & 7,41 & 7,65 \\
\hline Lisina $(\%)^{3}$ & 1,94 & 2,05 & 2,17 & 2,23 \\
\hline $\mathrm{Ca}(\%)^{3}$ & 1,62 & 1,62 & 1,62 & 1,62 \\
\hline $\mathrm{P}(\%)^{3}$ & 0,98 & 0,98 & 0,98 & 0,98 \\
\hline
\end{tabular}

${ }^{1}$ De acordo com Boscolo et al. (2002a).

2 De acordo com Meurer et al. (2003)

${ }^{3}$ De acordo com Rostagno et al. (2000). 


\section{Resultados e Discussão}

Os valores médios dos parâmetros físico-químicos da água das caixas, como pH, oxigênio dissolvido, condutividade elétrica e temperatura matutina e vespertina, foram, respectivamente, de 7,3; 5,1 mg/L; 0,31 mS/m; $25,7^{\circ} \mathrm{C}$ e $27,2^{\circ} \mathrm{C}$, dentro do recomendado para a piscicultura (Boyd, 1990; Sipaúba-Tavares, 1995).

O aumento nos níveis de farelo de soja na ração teve efeito linear positivo $(\mathrm{P}<0,01)$ sobre os valores de peso e comprimentos finais médios (Tabela 3), mas não influenciou $(\mathrm{P}>0,05)$ a condição corporal e o percentual de sobrevivência. Esses resultados confirmam informações de ElSayed (1999) de que o farelo de soja é adequado para a alimentação de tilápias-do-nilo. Os resultados deste experimento também estão de acordo com os encontrados por Souza et al. (2004), que verificaram que o farelo de soja éuma fonte protéica adequada para substituição da farinha de peixe no nível de $50 \%$ para tilápias-do-nilo durante a fase de reversão sexual.

O aumento do nível de farelo de soja em rações para tilápias-do-nilo durante a fase de reversão sexual possibilitou redução no nível de milho e farinha de vísceras e aumento no nível de óleo de soja. Essas alterações na fórmula das rações diminuíram os níveis de amido e dos aminoácidos sulfurosos metionina + cistina, que, por outro lado, promoveram aumento dos teores de lisina e fibra.

De acordo com El-Sayed (1999), tanto a farinha de vísceras quanto o farelo de soja são deficientes em alguns aminoácidos, inclusive lisina. No entanto, segundo Lovell (1988), o farelo de soja possui o melhor perfil aminoacídico de todos os alimentos protéicos de origem vegetal para os peixes. Entretanto, os níveis desse aminoácido são significativamente maiores no farelo de soja que na farinha de vísceras. Portanto, o aumento no nível de lisina é ocasionado principalmente pela ausência de milho nos maiores

Tabela 3 - Desempenho de alevinos de tilápia-do-nilo alimentados com as rações experimentais

\begin{tabular}{|c|c|c|c|c|c|}
\hline \multirow[t]{2}{*}{ Parâmetro } & \multicolumn{4}{|c|}{ Nível de farelo de soja (\%) } & \multirow[b]{2}{*}{ CV (\%) } \\
\hline & 0,0 & 16,0 & 34,0 & 42,0 & \\
\hline Peso final $^{1}$ (g) & 0,39 & 0,46 & 0,65 & 0,62 & 60,90 \\
\hline $\begin{array}{l}\text { Comprimento } \\
\text { final }^{2}(\mathrm{~cm})\end{array}$ & 2,22 & 2,35 & 2,61 & 2,62 & 20,24 \\
\hline Fator de condição & 0,34 & 0,32 & 0,32 & 0,33 & 39,01 \\
\hline Sobrevivência (\%) & 92,00 & 89,50 & 81,00 & 83,50 & 25,45 \\
\hline
\end{tabular}

${ }^{1}$ Efeito linear, $y=0,380294+0,00635731 x, r^{2}=0,92$.

2 Efeito linear, $y=2,21249+0,010278 x, r^{2}=0,96$. níveis de farelo de soja, pois o milho é reconhecidamente deficiente neste aminoácido (Rostagno et al., 2000). A explicação para o aumento linear do desempenho dos alevinos quando fornecidos níveis mais altos de farelo de soja pode ser a elevação dos níveis de lisina, primeiro aminoácido limitante nos alimentos utilizados para os peixes (Small \& Soares, 2000). A lisina é encontrada em alta concentração na carcaça dos peixes (Tantikitti \& Chimsung, 2001) e utilizada na síntese protéica (Mack, 1998), portanto, sua presença em níveis adequados é fundamental para o ganho de peso de tilápias. De acordo com Aguiar et al. (2005), a lisina é necessária para o desenvolvimento muscular de tilápias-do-nilo e importante para a proliferação das células musculares desta espécie na fase pós-larva.

O NRC (1993) indica o nível de 1,43\% de lisina para juvenis de tilápias-do-nilo, entretanto, este nível parece não ser adequado para esta espécie nesta fase. Meurer et al. (2005) observaram melhor desempenho de tilápias-donilo nesta fase ao fornecerem uma ração com 2,95\% de lisina. Boscolo et al. (2005a) não observaram diferenças $(\mathrm{P}>0,05)$ no desempenho desta espécie nesta fase quando forneceram rações com 2,05 a 2,34\% de lisina. Boscolo et al. (2005b) obtiveram os melhores desempenhos ao fornecerem rações com 2,09 a 2,51\% de lisina.

Wright et al. (1998) afirmaram que, apesar de esta espécie de peixe ser uma das que melhor utilizam a glicose como fonte de energia, a ingestão de alto nível de amido resulta em altos níveis de glicose sanguínea e sua volta a níveis basais é muito mais lenta que em mamíferos, resposta semelhante à de indivíduos diabéticos. Esses autores embasaram esta afirmação na falta de transportadores de glicose de alta eficiência (GLUT 4) nesta espécie. Portanto, é possível que a diminuição dos níveis deste nutriente nas rações tenha contribuído para o aumento do desempenho dos alevinos.

Entretanto, Krogdahl et al. (2005) demonstraram que a tilápia apresenta boa capacidade de digestão do amido, entre 71 e 95\%. Segundo Boscolo et al. (2002b) e Meurer (2002), tilápias-do-nilo utilizam o amido de maneira eficiente. Meurer et al. (2005) e Hayashi et al. (2002) avaliaram alimentos para tilápias-do-nilo na fase de reversão sexual e verificaram que o desempenho dos alevinos pode variar conforme o conteúdo de amido na ração, uma vez que os melhores resultados de desempenho foram obtidos com rações com 7,1 e $12,1 \%$ de amido, respectivamente. Portanto, a função do amido na dieta de tilápias-do-nilo nas fases iniciais de cultivo ainda precisa ser melhor compreendido. 


\section{Conclusões}

O farelo de soja é um alimento adequado para compor rações para tilápias-do-nilo durante a fase de reversão sexual e pode ser incluído em níveis de até $42 \%$.

\section{Literatura Citada}

AGUIAR, D.H.; BARROS, M.M.; PADOVANI, C.R. et al. Growth characteristics of skeletal muscle tissue in Oreochromis niloticus larvae fed on a lysine supplemented diet. Journal of Fish Biology, v.67, p.1287-1298, 2005.

BOSCOLO, W.R.; HAYASHI, F.; MEURER, F. et al. Farinha de peixe, carne e ossos, visceras e crisalidas como atractantes em dietas para alevinos de tilápias do Nilo (Oreochromis niloticus). Revista Brasileira de Zootecnia, v.30, n.5, p.1397-1402, 2001.

BOSCOLO, W.R.; HAYASHI, C.; MEURER, F. Digestibilidade aparente da energia e proteína bruta de alguns alimentos pela tilápia do Nilo (Oreochromis niloticus, L.). Revista Brasileira de Zootecnia, v.31, n.2, p.539-545, 2002a.

BOSCOLO, W.R.; HAYASHI, C.; MEURER, F. Farinha de mandioca (Manihot esculenta) na alimentação de alevinos de tilápia do Nilo (Oreochromis niloticus, L.). Revista Brasileira de Zootecnia, v.31, n.2, p.546-551, 2002b.

BOSCOLO, W.R.; HAYASHI, C.; MEURER, F. et al. Farinha de resíduos de filetagem de tilápias na alimentação de tilápia do Nilo (Oreochromis niloticus) na fase de reversão sexual. Revista Brasileira de Zootecnia, v.34, n.6, p.1807-1812, 2005a.

BOSCOLO, W.R.; MEURER, F.; FEIDEN, A. et al. Farinha de vísceras de aves em rações para a tilápia do Nilo (Oreochromis niloticus) durante a fase de reversão sexual. Revista Brasileira de Zootecnia, v.34, n.2, p.373-377, 2005b.

BOYD, C. Water quality in ponds for aquaculture. 1.ed. London: Birmingham Publishing Co, 1990. 482p.

EL-SAYED, A.F.M. Alternative dietary protein sources for farmed tilapia, Oreochromis spp. Aquaculture, v.179, p.149-168, 1999.

HAYASHI, C.; BOSCOLO, W.R.; SOARES, C.M. et al. Exigência de proteína digestível para larvas de tilápia do Nilo (Oreochromis niloticus), durante a reversão sexual. Revista Brasileira de Zootecnia, v.31, n.2, p.823-828, 2002.

KROGDAHL, A.; HEMRE, G.I.; MOMMSEN, T.P. Carboydrates in fish nutrition: digestion and absortion in post larval stages. Aquaculture Nutrition, v.11, p.103-122, 2005.
KUBITZA, F. Tilápia - tecnologia e planejamento na produção comercial. Jundiaí: Divisão de Biblioteca e Documentação, 2000. 285p.

LOVELL, T. Nutrition and feeding of fish. New York: Van Nostrand Reinhold, 1988. 260p.

MACK, S. Amino acids in broiler nutrition requirements and interrelations. In: SIMPOSIO INTERNACIONAL SOBRE NUTRIÇÃO DE AVES, 1998, Campinas. Anais... Campinas: Colégio Brasileiro de Nutrição Animal, 1993. p.468.

MEURER, F.; HAYASHI, C.; BOSCOLO, W.R. et al. Fontes protéicas suplementadas com aminoácidos e minerais para a tilápia do Nilo durante a reversão sexual. Revista Brasileira de Zootecnia v.34, n.1, p.1-6, 2005.

MEURER, F.; HAYASHI, C.; BOSCOLO, W.R. Digestibilidade aparente de alguns alimentos protéicos pela tilápia do Nilo (Oreochromis niloticus, L.). Revista Brasileira de Zootecnia, v.32, n.6, p.1801-1809, 2003.

MEURER, F.; HAYASHI, C.; BOSCOLO, W.R. et al. Lipídeos na alimentação de alevinos revertidos de tilápia do Nilo (Oreochromis niloticus, L.). Revista Brasileira de Zootecnia, v.31, n.2, p.566-573, 2002.

NATIONAL RESEARCH COUNCIL - NRC. Nutrient requirements of fish. Washington, D.C.: National Academy of Sciences, 1993. 124p.

ROSTAGNO, H.S.; ALBINO, L.F.T.; DONZELE, J.L. et al. Tabelas brasileiras para aves e suínos: composição de alimentos e exigências nutricionais. Viçosa, MG: Universidade Federal de Viçosa, 2000. 141p.

SANCHES, L.E.F.; HAYASHI, C. Effect of feeding frequency on Nile tilapia, Oreochromis niloticus (L.) fries performance during sex reversal in hapas. Acta Scientiarum, v.23, n.4, p.871876, 2001.

SIPAÚBA-TAVARES, L.H.S. Limnologia aplicada à aquicultura. Jaboticabal: Funep, 1995. 72p.

SMALL, B.C.; SOARES JR., J.H. Quantitative dietary lysine requeriment of juvenile striped bass Morone saxatilis. Aquaculture Nutrition, n.6, p.207-212, 2000.

SOUZA, S.R.; HAYASHI, C.; GALDIOLI, E.M. et al. Diferentes fontes de protéicas de origem vegetal para a tilápia do Nilo (Oreochromis niloticus), durante a reversão sexual. Acta Scientiarum - Animal Sciences, v.26, n.1, p.21-28, 2004.

TANTIKITTI, C.; CHIMSUNG, N. Dietary lysine requeriment of freshwater catfish. Aquaculture Research, n.32, suppl. 1, p.135-141, 2001.

UNIVERSIDADE FEDERAL DE VIÇOSA - UFV. SAEG - Sistema para análises estatísticas e genéticas. Versão 7.1. Viçosa, MG. 150p. (Manual do usuário).

WRIGHT JR., J.R.; O’HALI, W.; YANG, H. et al. GLUT-4 deficiency and severe peripheral resistance to insulin in the teleost fish tilapia. General and Comparative Endocrinology, n.111, p.20-27, 1998. 